\title{
Acromegaly and cardiovascular risk - In light of 30 cases
}

\author{
Askaoui $\mathrm{S}^{*}$, Mghari G and Ansari N \\ Department of Endocrinology, Diabetology and Metabolic Diseases, Med VI University Hospital Center, Marrakech, Morocco
}

\begin{abstract}
Purpose of the study: To analyze the different cardiovascular risk factors during acromegaly and their combination in the same patient.

Materials and method: prospective study, carried out over a period of 4 years at the endocrinology department of Med VI University Hospital of Marrakech. 30 files were identified. Methodologically, all cardiovascular risk factors were studied.

Results: The average age is 36 years with a sex ratio $(\mathrm{M} / \mathrm{F})$ of 0.7 . The duration of the disease at the time of diagnosis was on average 6 years. The family history was $16.7 \%$ of diabetes mellitus and heart disease.

A pathological BMI $\left(>25 \mathrm{Kg} / \mathrm{m}^{2}\right)$ was objectified in $60 \%$ of cases; $34 \%$ of these patients are in pre-diabetes, $43.3 \%$ are diabetics; a total of $77.3 \%$ of carbohydrate abnormalities, with a positive micro-albuminemia in three cases.

$13.4 \%$ of these patients have dyslipidemia and $23.4 \%$ are hypertensive, with a sedentary lifestyle noted in 16.7 cases, menopause in 3 patients and active smoking in 3 patients. $40 \%$ have at least two risk factors and $20 \%$ are affected by three cardiovascular risk factors.

Conclusion: Our study confirms the high incidence of cardiovascular risk factors in acromegalics. This fact is explained by the lipolytic effect, insulin resistance, hypervolemia and endothelial dysfunction due to excess growth hormone; hence the value of early diagnosis and comprehensive care.
\end{abstract}

\section{Introduction}

Acromegaly is a rare disease with an estimated incidence of 40 to 100 cases per million population. It is due to a hypersecretion of growth hormone $(\mathrm{GH})$, most often by a pituitary somatotropic adenoma, sometimes by a mixed adenoma with GH and very rarely by an ectopic secretion of GHRH [1].

It remains a serious disease, reducing life expectancy by an average of 10 years due to its cardiovascular and metabolic repercussions, which is why it is so important to systematically screen all risk factors and to take them into account charge.

The main objective of our study is to analyze the different cardiovascular risk factors during acromegaly and their combination in the same patient.

\section{Materials and method}

This is a prospective longitudinal type observational study conducted in the Department of Endocrinology, Diabetology and Metabolic Diseases of the Mohammed VI University Hospital of Marrakech, conducted over a four-year period (January 2015 to January 2019) and interested in patients whose diagnosis of acromegaly was confirmed by biological assays (IGF1 and negative OGTT test: GH>1 $\mathrm{ng} / \mathrm{ml}$ ) in addition to pituitary magnetic resonance imaging.

The following parameters have been studied:

- Age.

- The sex of the patients.

- The duration of evolution of the disease.

- Family history: Diabetes and heart disease.
- The body mass index (BMI).

- Blood pressure.

- Dyslipidemia.

- Dysglycemia.

- Renal impairment.

- Menopause.

- Smoking.

- Physical inactivity.

- All our patients benefited from a balance sheet including:

- Fasting blood glucose,

- Orally induced hyperglycemia (at 75 g glucose),

- glycated hemoglobin (HbA1c),

- Lipid balance: Total cholesterol, HDLc, LDLc and triglycerides.

- Micro-albuminuria of 24 hours - in case of diabetes

- Echocardiography (ECG) and echocardiography.

- Polysomnography.

*Correspondence to: Askaoui S, Imm Dalia 2 c, $\mathrm{N}^{\circ} 17$, Albadii, amerchich, Marrakech, Morocco, Tel: 0662286781; E-mail: saraaskaoui@yahoo.fr

Key words: acromegaly, growth hormone, cardiovascular risk

Received: February 07, 2019; Accepted: March 08, 2019; Published: March 12 2019 


\section{Results}

30 patients were included. The average age is 36 years old (17-63 years old) with a sex ratio ( $\mathrm{M} / \mathrm{F})$ of 0.7 . The age of onset of the disease at the time of diagnosis was on average 6 years (3-14 years), the family history was $16.7 \%$ of diabetes mellitus and heart disease.

Regarding the metabolic profile of these patients, a pathological BMI $\left(>25 \mathrm{Kg} / \mathrm{m}^{2}\right)$ was found in $60 \%$ of cases, while a mean waist circumference was found in women of $97 \mathrm{~cm}$ and men in $103 \mathrm{~cm} .34 \%$ of these patients have carbohydrate tolerance disorders with an average $\mathrm{HbAlc}$ of $6.2 \%$. These patients were placed under hygienic and dietary rules. $43,3 \%$ are diabetics with a mean $\mathrm{HbA} 1 \mathrm{c}$ of $11 \%$, are insulin-treated and under metformin; a total of $77.3 \%$ carbohydrate abnormalities, with microalbuminemia positive in three cases, put under inhibitor of the conversion enzyme. $13.4 \%$ of patients have dyslipidemia put under statins.

In addition, $23.4 \%$ of these patients are hypertensive with ventricular hypertrophy and $23.3 \%$ have sleep apnea syndrome. Physical inactivity was noted in four cases, menopause in three patients and active smoking in three patients (Figure 1).

Twelve have at least two risk factors and six are affected by three risk factors.

Hypothalamic-pituitary MRI revealed the presence of a pituitary macro-adenoma in $93.3 \%$ of cases and in $6.7 \%$ of cases it was microadenoma. Regarding the etiological assessment, it was a somatotropic adenoma in $55.6 \%$ of cases, a somato-prolactinic adenoma in $20 \%$, a mammosomatotropic adenoma in $14.4 \%$ and the nature of adenoma is not yet determined in $10 \%$ of cases (Figure 2).

$90 \%$ of these patients underwent at least one first-stage pituitary surgery. $56.7 \%$ of cases are under medical treatment second intension (somatostatin analogue). 6.7\% of cases are considered in remission.

The impact of surgical treatment of acromegaly in patients with abnormalities of carbohydrate metabolism was notable, considering the

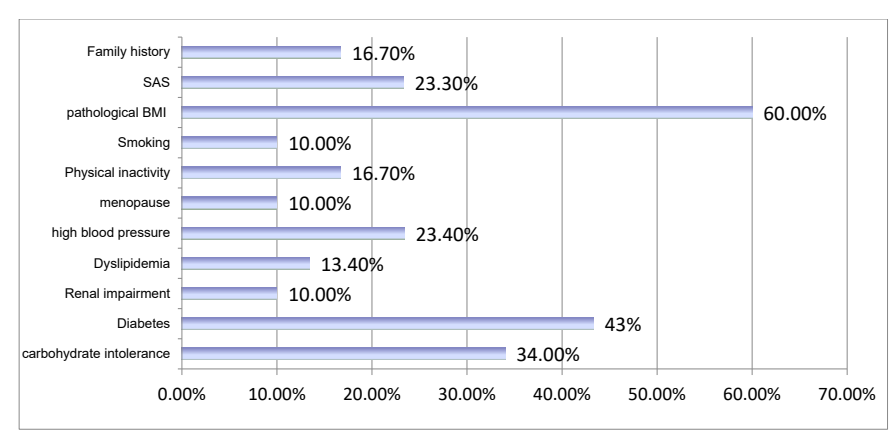

Figure 1. Cardiovascular risk factors in our series

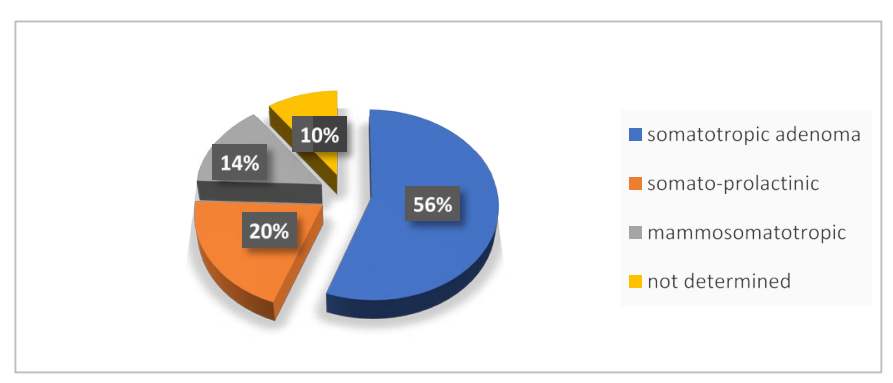

Figure 2. Immunohistochemical profile of the adenoma improvement of the metabolic profile in all pre-diabetics (the average HbAlc increased to 5.9\%), the decrease in insulin requirement in all diabetics with a sharp decrease in HbAlc average to $8.6 \%$ and the tendency to cure diabetes in two patients whose disease is controlled, while hypertension remained.

\section{Discussion}

Acromegaly is a rare disease, due to a hypersecretion of growth hormone most often by a pituitary adenoma, rarely by ectopic secretion of GHRH and may sometimes integrate into syndromic disorders such as Wermer's syndrome or endocrine neoplasia type 1, Carney's syndrome and McCune Albright syndrome [2,3].

It remains a lethal disease due to its metabolic complications (glucose intolerance, diabetes, dyslipidemia); cardio-vascular complications (hypertension, cardiomegaly, left ventricular hypertrophy, coronary artery disease and arrhythmia); its respiratory complications (sleep apnea syndrome) and neoplastic complications (especially colic), which are responsible for high morbidity and mortality, reducing the expectation and the quality of life of the patients [4].

Diabetes secondary to acromegaly is a frequent complication, the prevalence is estimated between $20 \%$ and $25 \%$, often curable [5,6]. The pathophysiological mechanism involved is insulin resistance, associated with the hyperglycemic action of the hormones of growth and IGF1, responsible for the accentuation of gluconeogenesis and hepatic glycolysis [7-9].

Its main risk factors are high levels of growth hormone, prolonged illness, advanced age, and a family history of diabetes and hypertension [10].

There are no particularities regarding the diagnostic modalities of diabetes in acromegalic patients; however, the latter must be done outside periods of imbalance and in the absence of hypoglycemia likely to stimulate the secretion of $\mathrm{GH}$.

The various therapeutic means of acromegaly have a varied effect on carbohydrate metabolism: in most cases, the surgical treatment allows the concomitant cure of diabetes, the somatostatin analogues and pasireotide have a hyperglycemic effect, and the antagonists of the GH have a hypoglycemic effect [11-17].

In addition to metabolic disturbances, excess growth hormone can induce hypertrophic cardiomyopathy, coronary insufficiency and often an increase in arterial pressure - 3 times more common in acromegalics and not always reversible; this is due to the inhibition of the secretion of the atrial natriuretic factor, subsequently increasing the sodium tubular reabsorption and thus promoting the water-soluble retention; not to mention the added role of endothelial dysfunction [18-21].

In our series, approximately $77,3 \%$ of cases present metabolic disorders with a tendency to high doses of insulin prior to surgery and to cure diabetes after successful surgery, which is consistent with literature data.

\section{Conclusion}

Our study, in agreement with the results of other previous studies, confirms the high prevalence of cardiovascular risk factors in the acromegalic patient, hence the importance of systematic screening and early and comprehensive care. This is to prevent progression to cardiovascular complications, the leading cause of death in acromegalics. 


\section{Conflicts of interest}

No.

\section{References}

1. Belayet H, William MD (2017) Acromegaly. Medicine 45: 480-483.

2. Giustina A, Chanson P, Kleinberg D, Bronstein MD, Clemmons DR, et al. (2014) Expert consensus document: A consensus on the medical treatment of acromegaly. Nat Rev Endocrinol 10: 243-248. [Crossref]

3. Ilie L, Korbonits M (2016) Diagnosis of acromegaly.

4. Pivonello R, Auriemma RS, Grasso LF, Pivonello C, Simeoli C, et al. (2017) Frequency of acromegaly in adults, with diabetes or glucose intolerance and estimated prevalence in the general population. Pituitary 20:46-62.

5. Fieffe S, Morange I, Petrossians P, Chanson P, Rohmer V, et al. (2011) Diabetes in acromegaly, prevalence, risk factors, and evolution: data from the French acromegaly registry. Eur J Endocrinol 164: 877-884. [Crossref]

6. Găloiu S, Poiană C (2015) Current therapies and mortality in acromegaly. J Med Life 8: 411-415. [Crossref]

7. Hannon AM, Thompson CJ, Sherlock M (2017) Diabetes in patients with acromegaly. Curr Diab Rep 17: 8. [Crossref]

8. Delemer B (2016) Acromégalie et diabète. Médecine et maladies métaboliques 10 :712716.

9. Ben Nacef I, Ben Said R, Ouslati I (2014) Diabète et acromégalie. Diabetes and Metabolism 40: 67.

10. Elwadeh I, Sebaitre N, Kabbaj F (2013) Facteurs de risque de survenue de diabète au cours de l'acromégalie (à propos de 19 cas). Diabetes and Metabolism 39: 114.

11. Rosario PW (2011) Diabetes in acromegaly, prevalence, risk factors, and evolution: Data from the French acromegaly registry. Pituitary 2011: 217-221.
12. Leonart LP, Ferreira VL, Tonin FS, Fernandez-Llimos F, Pontarolo R (2018) Medical treatments for acromegaly: A systematic review and network meta-analysis. Value in Health 21: 874-880.

13. Dal J, Hoyer KL, Pedersen SB, Magnusson NE, Bjerring P, et al. Growth hormone and insulin signaling in acromegaly: Impact of surgery versus somatostatin analog treatment. J Clin Endocrinol Metab 101: 3716-3723. [Crossref]

14. Gadelha MR, Wildemberg LE, Bronstein MD, Gatto F, Ferone D (2017) Somatostatin receptor ligands in the treatment of acromegaly. Pituitary 20: 100-108. [Crossref]

15. Caron P, Petersenn S, Tabarin A, et al. Évaluation métabolique au cours du traitemen de première intention par lanréotide $120 \mathrm{mg}$ chez 90 patients atteints d'acromégalie: données de l'étude PRIMARYS.

16. Colao A, Auriemma RS, Savastano S, Galdiero M, Grasso LF, et al. (2009) Glucose tolerance and somatostatin analog treatment in acromegaly: a 12-month study. $J$ Clin Endocrinol Metab 94: 2907-2914. [Crossref]

17. Ernaga Lorea A, Eguílaz Esparza N, Ollero García-Agulló MD, García Mouriz M, Iriarte Beroiz A, et al. (2017) Glucose metabolism before and after treatment in patients with acromegaly. Endocrinol Diabetes Nutr 64: 363-368. [Crossref]

18. Guo X, Fu H, Pang H, Xing B (2014) Risk of left ventricular hypertrophy and diastolic and systolic dysfunction in Acromegaly: A meta-analysis. $J$ Clin Neurosci 48: 28-33. [Crossref]

19. Amani MEA, Nait BahloulN, Benabadji N(2014) Dyslipidémie et hypersomatotropisme Diabetes and Metabolism 35: A82.

20. Lombardi G, Galdiero M, Auriemma RS, Pivonello R, Colao A (2006) Acromegaly and the cardiovascular system. Neuroendocrinology 83: 211-217. [Crossref]

21. Ozbek M, Erdogan M, Dogan M, Akbal E, Ozturk MA, et al. (2011) Serum heart-type fatty acid binding protein levels in acromegaly patients. J Endocrinol Invest 34: 576579. [Crossref]

Copyright: (C2019 Askaoui S. This is an open-access article distributed under the terms of the Creative Commons Attribution License, which permits unrestricted use, distribution, and reproduction in any medium, provided the original author and source are credited. 